\title{
Effects of continual burial by sediment on morphological traits and dry mass allocation of Suaeda salsa seedlings in the Yellow River estuary: An experimental study
}

\author{
Zhigao Sun ${ }^{\mathrm{a}, \mathrm{b}, *}$, Hongli Song ${ }^{\mathrm{a}, \mathrm{c}}$, Wenguang Sun ${ }^{\mathrm{a}, \mathrm{c}}$, Jingkuan Sun ${ }^{\mathrm{b}}$ \\ ${ }^{a}$ Key Laboratory of Coastal Environmental Processes and Ecological Remediation, Yantai Institute of Coastal Zone Research, Chinese Academy of Sciences, \\ Yantai, Shandong 264003, PR China \\ b Shandong Provincial Key Laboratory of Eco-Environmental Science for Yellow River Delta, Binzhou University, Binzhou, Shandong 256603, PR China \\ ' University of Chinese Academy of Sciences, Beijing 100049, PR China
}

\section{A R T I C L E I N F O}

\section{Article history:}

Received 6 June 2013

Received in revised form 10 January 2014

Accepted 25 March 2014

Available online 4 May 2014

\section{Keywords:}

Continual burial

Morphological trait

Suaeda salsa

Coastal marsh

Yellow River estuary

\begin{abstract}
A B S T R A C T
Information on the effects of continual burial by sediment on seedling survival and morphological growth in coastal marsh remains scarce. A greenhouse experiment was conducted to determine the effects of continual burial on seedling mortality, growth and dry mass allocation of Suaeda salsa in the coastal marsh of the Yellow River estuary. The seeds were planted at $0.5 \mathrm{~cm}$ depth in plastic pots filled with unsterilized sediment on May 5, 2012. A depth of $8 \mathrm{~cm}$ was chosen as the maximum of continual burial according to the sedimentary rate $(6-7 \mathrm{~cm})$ in the coastal marsh at seedling stage. Two weeks after emergence, seedlings were artificially buried to depths of 0 (D0, no burial), 33\% (D33, burial of $1 \mathrm{~mm} \mathrm{~d}^{-1}$ ), $67 \%$ (D67, burial of $2 \mathrm{~mm} \mathrm{~d}^{-1}$ ), $100 \%$ (D100, burial of $3 \mathrm{~mm} \mathrm{~d}^{-1}$ ) and 133\% (D133, burial of $4 \mathrm{~mm} \mathrm{~d}^{-1}$ ) of their mean height, with 20 days in total. Results showed that seedling height, stem and taproot diameter, number of branch, hypocotyl and taproot length, and dry mass were significantly affected by burial depth $(p<0.05)$. No seedlings died in the four burial treatments. Seedling heights in the D33 and D67 treatments were higher than those of the other treatments, indicating that shallow and moderate burials exhibited greater stimulation to seedling growth. Although stem diameter, number and length of branch, and dry mass of seedlings were stimulated in the four burials, the greatest stimulatory effect on stem diameter was observed in the D100 treatment while that on number and length of branch and dry mass occurred in the D67 treatment. With increasing burial depth (D67, D100 and D133), seedling taproot diameter and length decreased while hypocotyl length increased, reflecting that hypocotyl elongation might occur at the expense of development of the root system. The responses of morphological traits and dry mass allocation of S. salsa seedlings to the burial treatments indicated that they might have a special strategy to tolerate the continual burial in the coastal marsh of the Yellow River estuary. The use of thin-layer burial $\left(2 \mathrm{~mm} \mathrm{~d}^{-1}\right)$ to promote seedling vigor in degraded $S$. salsa marsh was feasible, and our study provided valuable information for the restoration of $S$. salsa marsh during seedling growth.
\end{abstract}

(c) 2014 Elsevier B.V. All rights reserved.

\section{Introduction}

Coastal marshes are complex and dynamic, continually changing due to the action of tides and waves. Plants growing on coastal marshes are exposed to a number of extreme conditions, such as high wind velocities, drastic temperature fluctuations, high potential evapotranspiration, frequent ebb and flow of tide, inundation by seawater and burial in sediment (Baldwin and Maun, 1983;

\footnotetext{
* Corresponding author. Tel.: +86 0535 2109121; fax: +86 05352109000 E-mail address: zgsunyic@126.com (Z.Sun).
}

Maun, 1998; Deng et al., 2008). Among them, sediment burial has been recognized as a major selective force in the evolution of seed germination, seedling emergence, seedling establishment and survivorship of seedling and adult plants (Maun, 1994). Different sediment disturbances may result in the seeds, seedlings and adult plants being directly damaged and killed or buried within the sediment to different extent (Chandrasekara and Frid, 1998). Marsh plants also evolve a variety of adaptations that allow survival, growth and reproduction under relatively stressful and variable burial conditions (Redmann and Qi, 1992; Maun, 1994; Thampanya et al., 2002; Deng et al., 2008; Li et al., 2011; Wen et al., 2012). 
Sediment burial may increase the vulnerability of the plants (Maun and Riach, 1981), and their survivorship and growth are directly related to the depth at which seedling buried. Burial at shallow depths generally has significant stimulation to the morphological traits of plants (such as leaf area and thickness, biomass, length of leaf, taproot, stem and internode, number of leaf, internodes and tillers, seed production) (Disraeli, 1984; Zhang and Maun, 1990; Maun et al., 1996; Chen and Maun, 1999; Thampanya et al., 2002; Zhao et al., 2007; Deng et al., 2008), which is presumably due to the major changes in sediment nutrient status, temperature, microorganism composition, mycorrhizal fungi and sediment aeration (Maun, 1998). Some species may actually require moderate burial in sediment to maintain high vigor (van der Putten et al., 1993). However, high levels of burial tended to inhibit plant growth (Maun, 1998), which is dependent on whether plants can overcome the suspension of photosynthetic activity and emerge from the burial deposit and then reinstate physiological activity (Perumal and Maun, 2006). Thus, there is a threshold of burial for each plant to maximize vigor. Below the threshold level, the growth of plants was stimulated by burial. As the level increased over the threshold, the response of plants might become deteriorated in growth and vigor (Zhao et al., 2007).

There has been intense and increasing interest in understanding the responses of seedlings to burial because burial is an important factor controlling the distribution and composition of plants in different communities (Maun and Lapierre, 1984; Maun, 1994, 1996; Maun et al., 1996; Brown, 1997; Terrados et al., 1997; Chandrasekara and Frid, 1998; Thampanya et al., 2002; Zhao et al., 2007; Sun et al., 2010). Studies on the responses of seedling survival and morphological growth to burial have been widely reported, which mainly focused on arid and semi-arid dune (Sykes and Wilson, 1990; Maun, 1996; Brown, 1997; Liu et al., 2006; Yang et al., 2007; Zhao et al., 2007; He et al., 2008), coastal/lacustrine dune (Maun, 1994, 1998; Maun et al., 1996; Franks and Peterson, 2003), coastal marsh (Deng et al., 2008; Sun et al., 2010) and mangrove swamp (Lee et al., 1996; Terrados et al., 1997; Thampanya et al., 2002). Current studies mostly focus on single one-time burial, while information on the tolerance or stimulation responses to continual burial events is lacking. Actually, plants in natural habitats are most often exposed to dynamic and stochastic disturbance episodes, and the chances of seedling survival may be much higher since continual burial maintains a low stressful environment around plants compared to single one-time burial events (Maun et al., 1996).

The Yellow River is well known as a sediment-laden river. Every year, approximately $1.05 \times 10^{7}$ tons of sediment is carried to the estuary and deposited in the slow flowing landform, resulting in vast floodplain and special marsh landscape (Xu et al., 2002). Sediment deposition is an important process in the formation and development of coastal marshes in the Yellow River Delta. The deposition rate of sediment in the Yellow River not only affects the formation rate of coastal marshes, but also influences water or salinity gradients and the succession of plants from the land to the sea. Suaeda salsa is the most prevalent plant in the coastal marshes of the Yellow River estuary. As a pioneer plant, it is often affected by the sediment of tide physical disturbance, which is generally dependent on the prevailing wind velocities. It was reported that the annual runoff of the Yellow River reached the maximum of 49.1 billion $\mathrm{m}^{3}$ in 1983 and then decreased and fluctuated at 20.0 billion $\mathrm{m}^{3}$ until 1996 (Cui et al., 2009). During 1997-2002, the annual runoff was mainly below 10.0 billion $\mathrm{m}^{3}$. Low flows exhibited by the Yellow River led to significant decreases in freshwater and sediment inputs to the estuary, and the S. salsa marshes therein did not grow better and exhibited significant degraded status due to the sediment salinity level over the optimum ecological threshold for the plants (Cui et al., 2008). In order to restore the degraded marshes, the nation carried out "water and sand regulation project" (WSRP) in 2002 by increasing the supply of freshwater and sediment for the estuary. During WSRP, the river water frequently flooded the $S$. salsa marshes near the estuary and the sediment salinity could be maintained around the optimum threshold for S. salsa. Moreover, considerable sediments were continually deposited (approximately $5-6 \mathrm{~cm}$ thick) in the marsh during WSRP, which might significantly influenced seedling emergence and growth of S. salsa (Mou, 2010). However, little is known about the effects of sediment continual burial on seedling morphological traits of S. salsa in the coastal marshes of the Yellow River estuary.

Although freshwater subsidy was another important factor in maintaining $S$. salsa marshes, in this paper, we mainly focused on the effects of continual burial on seedling morphological growth and dry mass allocation because, during WSRP, the influences of sedimentation on seedlings were more drastic than those of freshwater subsidy. It was anticipated that there would have a threshold of burial to maximize plant growth vigor, and morphological traits and dry mass allocation would respond differently to continual burial. Objectives of this paper were (i) to determine the responses of morphological traits and dry mass allocation of $S$. salsa seedlings to continual burials, and (ii) to determine the threshold of continual burial required to maximize seedling growth vigor.

\section{Materials and method}

\subsection{Study site}

This study was conducted in a greenhouse in the Shandong Key Laboratory for Eco-Environmental Science of the Yellow River Delta in Binzhou University. The sediment used in this experiment was sampled from the coastal marsh in the Yellow River estuary [sample depth: $15 \mathrm{~cm}$; sediment salinity (water extracted salinity): $1.49 \pm 0.27 \%(n=5)]$, which is located in the Nature Reserve of Yellow River Delta $\left(37^{\circ} 35^{\prime} \mathrm{N}-38^{\circ} 12^{\prime} \mathrm{N}, 118^{\circ} 33^{\prime} \mathrm{E}-119^{\circ} 20^{\prime} \mathrm{E}\right)$ in Dongying City, Shandong Province, China. The nature reserve is of typical continental monsoon climate with distinctive seasons. The annual average temperature is $12.1^{\circ} \mathrm{C}$ and the frost-free period is $196 \mathrm{~d}$. Annual evaporation is $1962 \mathrm{~mm}$ and annual precipitation is $551.6 \mathrm{~mm}$, with about $70 \%$ of precipitation occurring between June and August. The soils in the study area are dominated by intrazonal tide soil and salt soil, and the main vegetations include Phragmites australis, S. salsa, Triarrhena sacchariflora, Myriophyllum spicatum and Tamarix chinensis (Sun et al., 2012). Coastal marsh is the main marsh type, with an area of $964.8 \mathrm{~km}^{2}$, accounting for $63.06 \%$ of the total area of the Yellow River Delta (Cui et al., 2009). As the pioneer plant in coastal marshes, S. salsa is often affected by the sediment deposition of tidal disturbance, bioturbation and Yellow River flooding during WSRP. The sedimentary rate in the $S$. salsa marsh is about $9-10 \mathrm{~cm} \mathrm{yr}^{-1}$, and approximately $6-7 \mathrm{~cm}$ occurs at the seedling stage due to the significant effects of both tidally induced sediment and WSRP (Mou, 2010).

\subsection{Experimental method}

Seeds of S. salsa were collected in the fall of 2011 from four typical regions of the Yellow River estuary. Seeds were collected from multiple individuals (about 800 individuals) in each region and mixed together. Seeds were cleaned, dried at room temperature for 2-3 weeks, then stored at $8^{\circ} \mathrm{C}$ under dry, dark conditions. The planting was carried out on May 5, 2012. The sediment was poured into each plastic pot ( $28 \mathrm{~cm}$ in diameter, $32 \mathrm{~cm}$ in height) up to the same depth $(22 \mathrm{~cm})$ and moistened, then the seeds $(n=15)$ were 
planted in each pot and covered with sediment at $0.5 \mathrm{~cm}$ burial depth. The drainage outlet at the bottom of the pots was covered with strips of nylon mesh to prevent the loss of sediment while allowing drainage of excess water. During the experiment, the pots were regularly watered with freshwater, and every two days with seawater in order to better simulate the field conditions and avoid excessive salinity accumulating in sediment as seawater was used alone. The salinity of sediment in each pot was monitored daily and adjusted to the field condition every four days. Temperature in the greenhouse was maintained at $23^{\circ} \mathrm{C}$ during the day ( $16 \mathrm{~h}$ photoperiod) and $14{ }^{\circ} \mathrm{C}$ at night [approximating the average temperatures in May $\left(22.5^{\circ} \mathrm{C}\right.$ during the day and $13.6^{\circ} \mathrm{C}$ at night $\left.)\right]$.

Two weeks after seedling emergence (May 20), we chose 4-5 vigorous seedlings randomly in each pot and the others were removed. The height of each seedling in every pot was measured and the mean height $(5.5 \pm 0.7 \mathrm{~cm})$ above the sediment surface was calculated. In order to conveniently calculate the continual burial rate, a depth of $6 \mathrm{~cm}$ was chosen as the mean height of seedlings in the actual study. Moreover, according to the above-mentioned sedimentary rate in the coastal marsh of the Yellow River estuary, a depth of $8 \mathrm{~cm}$ was chosen as the maximum of continual burial. On May 21 (16 days after sowing), the original heights of seedlings were measured, then seedlings were artificially buried to depths of 0 (D0, no burial), 33\% (D33, burial of $1 \mathrm{~mm} \mathrm{~d}^{-1}$ ), 67\% (D67, burial of $2 \mathrm{~mm} \mathrm{~d}^{-1}$ ), 100\% (D100, burial of $3 \mathrm{~mm} \mathrm{~d}^{-1}$ ) and 133\% (D133, burial of $4 \mathrm{~mm} \mathrm{~d}^{-1}$ ) of their mean height until June 10, with 20 days in total. For burial, additional sediment was added to the pots according to the different burial depths every day. Seedlings were kept vertical while being buried. As mentioned previously, approximately $6-7 \mathrm{~cm}$ sediment occurs at the seedling stage due to the significant influences of both tidally induced sediment and WSRP. Thus, the four burial treatments can be divided into three groups according to the total sediment depth during the experiment: (i) deep burial (D100, D133): total sediment depths at the D100 and D133 treatments $(6 \mathrm{~cm}$ and $8 \mathrm{~cm}$, respectively) approximate the actual maximum of sediment depth $(6-7 \mathrm{~cm})$; (ii) shallow burial (D33): total sediment depth at the D33 treatment $(2 \mathrm{~cm})$ is much lower than the actual maximum of sediment depth, and (iii) moderate burial (D67): total sediment depth at the D67 treatment $(4 \mathrm{~cm})$ is higher than shallow burial, but lower than deep burial. There were seven replicates per treatment, with 35 pots in total.

After being buried, the heights of seedlings were determined on May 31 (26 days), June 5 (31 days), June 10 (36 days), June 15 (41 days), June 20 (46 days) and June 25 (51 days), respectively. Seedling heights were measured from the sediment surface to the seedling top, which was similar with the measurement reported in

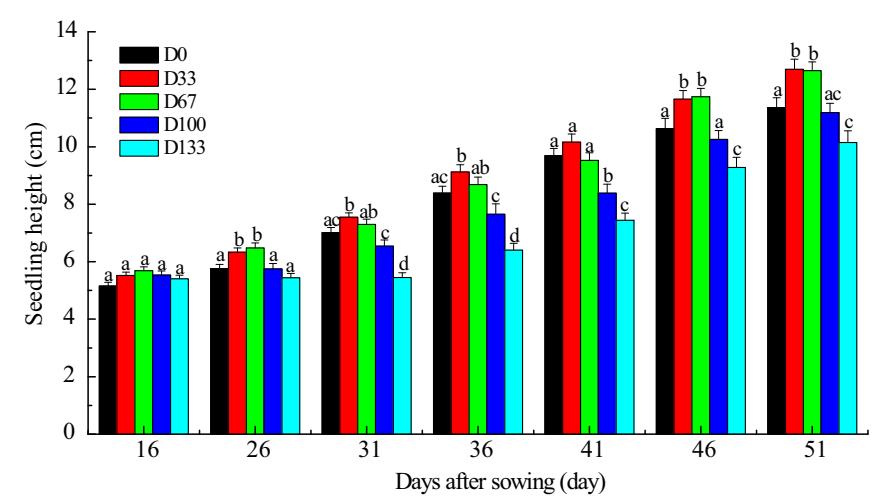

Fig. 1. Mean $( \pm$ SE) height of seedlings continually buried in sediment to depths of 0 (D0), 33\% (D33), 67\% (D67), 100\% (D100) and 133\% (D133) of their mean height in different periods. For each period, values with the same superscript letters are not significantly different at $p<0.05$ according to Tukey's test. related studies (Li et al., 2006; Zhao et al., 2007; Sun et al., 2010). Since the seedlings were small and had no branch during the burial, stem diameter, number and length of branch were not measured. After the burial was finished on June 10, the stem diameter, number and length of branch were measured every 5 days. The experiment was terminated on June 26. All seedlings were harvested and the survivorship of seedlings was determined. The seedlings were dug out by trowel, and care was taken to collect as many roots belonging to the seedling as possible. Seedlings were then taken to the laboratory and stem diameter, number and length of branch, hypocotyl length, taproot diameter and length were measured. After the seedlings were separated into root, stem and leaf, each fraction was weighed until it reached a constant mass after drying at $80^{\circ} \mathrm{C}$ for $48 \mathrm{~h}$.

\subsection{Calculation}

The absolute height growth rate $\left(A H G R, \mathrm{~mm} \mathrm{~d}^{-1}\right)$ and relative height growth rate $\left(R H G R, \mathrm{~mm} \mathrm{~cm}^{-1} \mathrm{~d}^{-1}\right)$ of seedlings was calculated by the following equations (Zhao et al., 2007):

$A H G R=\frac{H_{2}-H_{1}}{T_{2}-T_{1}}, \quad R H G R=\frac{H_{2}-H_{1}}{H_{1}\left(T_{2}-T_{1}\right)}$

where $H_{1}, H_{2}$ were seedling heights after starting the burial on May $21\left(T_{1}\right)$ and at harvest on June $26\left(T_{2}\right)$, respectively and $T$ was time in days.

\subsection{Statistical analysis}

All statistical analyses of experimental data were performed using software SPSS Version 15.0 of Statistical Software Package (SPSS Inc., Chicago, U.S.A.). The Shapiro-Wilk test was applied to identify the normality of data before means and the analysis of variance (ANOVA) were used. The test rejected the hypothesis of normality as the $p$-value was less than or equal to 0.05 . The results were presented as means of the replications, with standard error (S.E.). The effects of continual burial on seedling height, stem diameter, number and length of branch, hypocotyl length, taproot diameter and length, and dry mass were analyzed using ANOVA among the treatments. If ANOVA showed significant differences, multiple comparison of means was undertaken by Tukey's test with a significance level of $p=0.05$.

\section{Results}

\subsection{Effects of continual burial on seedling morphology}

\subsubsection{Seedling survivorship and height}

No seedlings died in the four burial treatments. Seedling heights at the $26 \mathrm{th}, 31 \mathrm{st}, 36 \mathrm{th}, 41 \mathrm{st}, 46 \mathrm{th}$ and $51 \mathrm{st}$ day were significant different among the five treatments $(p<0.001)$ (Table 1$)$. After sowing for 16 days, the seedling heights were approximated in the five treatments, and then the values at the shallow (D33) and moderate (D67) burials surpassed the ones at the unburied (D0) or deep burials (D100 and D133). Except the 16th day, seedling heights at the deep burials were always lower than the values at the unburied or moderate burials (Fig. 1). AHGR and RHGR were higher in the D33 and D67 treatments than in the D0, D100 and D133 treatments (Fig. 2), indicating that seedlings in the shallow and moderate burials had higher growth potential.

\subsubsection{Stem diameter, number and length of seedling branch}

The stem diameter, number and length of seedling branch were significant different among the five treatments $(p<0.05)$ (Table 1$)$. During the experiment, the stem diameters of the D100 and D133 


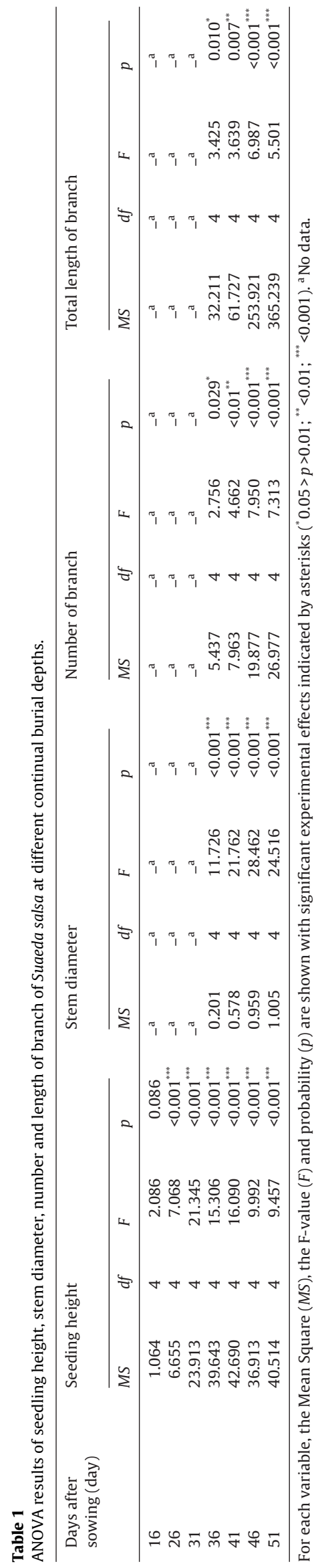

treatments were higher than those of the D0, D33 and D67 treatments, while the values of the D33 and D67 treatments were higher than those of the D0 treatment (Fig. 3A). The number and length of seedling branch were higher in the D33, D67 and D100 treatments than in the D0 and D133 treatments. At the 36th and 41st day, the number and length of branch were lower in the D133 treatment than in the D0 treatment, while at the 46th and 51st day, the trends were opposite (Fig. 3B and C).

\subsubsection{Hypocotyl and taproot of seedlings}

After 51 days, the hypocotyl length, taproot diameter and length of seedlings were significantly affected by burial depth $(p<0.05)$ (Table 2). The lengths of seedling hypocotyl were lower in the D33 and D67 treatments than in the D100 and D133 treatments (Fig. 4A). The variations of taproot diameter and length of seedlings were opposite to those of hypocotyl length, with the highest values occurred in the D33 and D67 treatments, respectively (Fig. 4B and C). With increasing burial depth (D67, D100 and D133), taproot diameter and length decreased while hypocotyl length increased.

\subsection{Effects of continual burial on seedling dry mass and dry mass allocation}

The dry mass of seedlings and their different parts (root and leaf) were significantly affected by burial depth $(p<0.05)$ (Table 2$)$. At shallow and moderate burials, the dry mass of seedlings and their different parts (stem and leaf) increased with increasing burial depth, with the highest values occurring in the D67 treatment. While at deep burials, the values decreased with increasing burial depth (Fig. 5A). Although the dry mass of seedlings was less in the D100 treatment than in the D67 treatment, the value was still higher than in the other treatments. The dry mass allocations to root, stem and leaf were altered by burial depth, and the highest root-mass, stem-mass and leaf-mass ratios occurred in the D100, D133 and D67 treatments, respectively (Fig. 5B).

\section{Discussion}

As the pioneer species in the coastal marshes of the Yellow River estuary, seedlings of $S$. salsa might be easily buried by sediment to various depths during establishment in late spring. Continual burial by tide-deposited sediment (Cheplick and Grandstaff, 1997) or flood-deposited sediment during the WSRP of Yellow River (Cui et al., 2009) was a critical episode for $S$. salsa seedling establishment in the habitats. Two questions were answered in our study: (i) how did the continual burials influence the morphological traits of S. salsa seedlings? and (ii) which burial depth was optimal for maximizing $S$. salsa seedling vigor?

\subsection{Seedling performance at continual burial disturbances}

The continual burial experiment of $S$. salsa showed that seedling survivorship was not significantly affected by burial depth and no seedlings died in the four treatments. Different results were reported by some single one-off burial experiments. Sykes and Wilson (1990) reported that only a few species survived complete burial but all species survived partial burial to $66 \%$ of their height. Maun et al. (1996) showed that all Cirsium pitcheri seedlings survived the shallow burials, $80 \%$ seedlings survived the moderate burial and none survived the complete burial. Sun et al. (2010) indicated that only about $18.06 \pm 5.32 \%$ seedlings survived as they were completely buried, and no seedling survived as the burial depth reached $133 \%$ of their height. One primary reason was related to the difference of length of time required to recover from burial. Single burial of plants precipitated a set-back and it took a long 

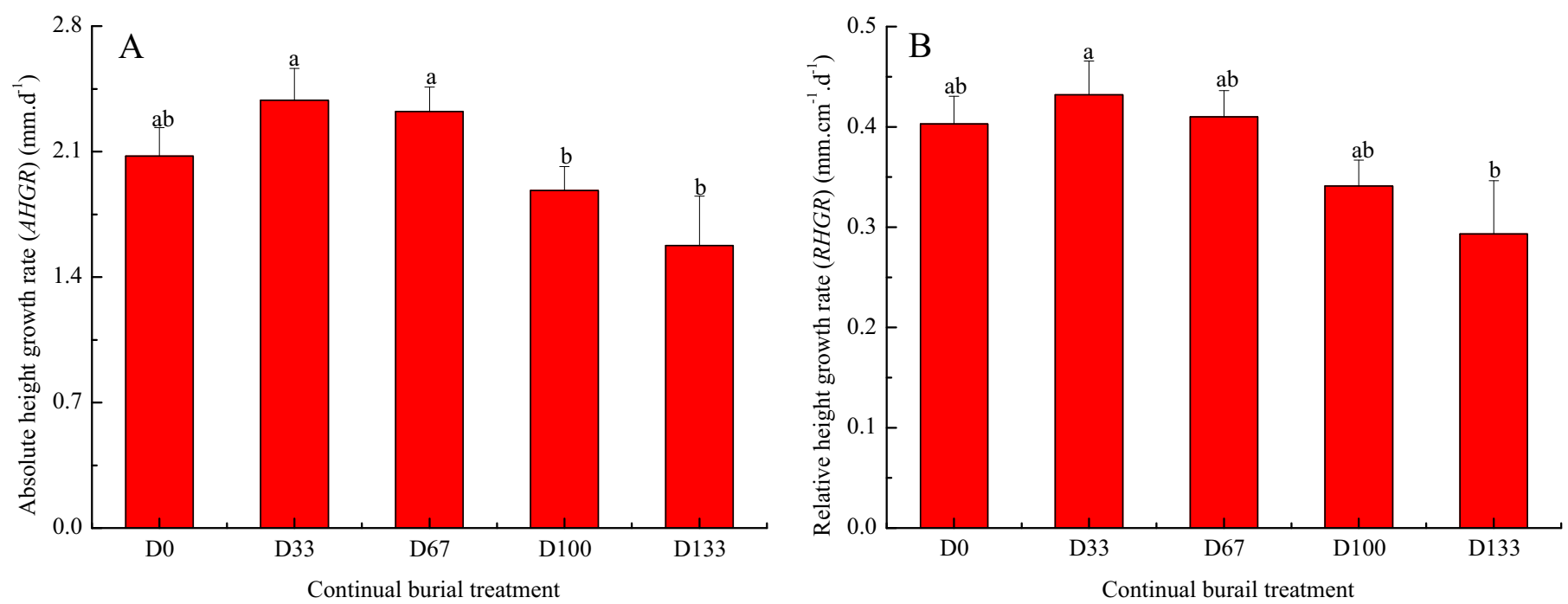

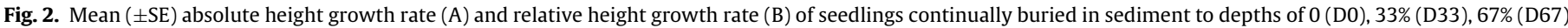
and $100 \%$ (D100) of their mean height after 51 days. Values with the same superscript letters are not significantly different at $p<0.05$ according to Tukey's test.

time for plants to recover. Once the plants can not emerge from the burial deposit and reinstate physiological activity within a few days after a one-off burial episode (Harris and Davy, 1987; Perumal and Maun, 2006), they will probably be killed due to the exhaustion of stored energy and the suspension of photosynthetic activity. By comparison, the continual burial generally maintains a low stressful environment around seedlings, and they may adjust quickly to the continual and smaller burial deposits.

The experiment indicated that the morphological traits of $S$. salsa seedlings were greatly influenced by continual burial depth. Shallow (D33) and moderate (D67) burials exhibited greater stimulation to seedling height (stimulation was greatest at the D33 treatment) while deep burials (D100 and D133) were inhibitory. Although the stem diameter, number and length of branch and dry mass accumulation of seedlings were stimulated in the four burials, the greatest stimulatory effect on stem diameter was observed in the D100 treatment while that on number and length of branch and dry mass occurred in the D67 treatment. The variations of these morphological traits would be favorable for maintaining $S$. salsa populations in natural habitat which was most often exposed to continual and stochastic disturbance events. A number of plants also use some of these morphological responses to adapt burials. Zhao et al. (2007) indicated that the heights of Nitraria sphaerocarpa seedlings in the partial burial treatment were higher than those in the control treatment. Sykes and Wilson (1990) reported that Hydrocotyle bonariensis responded to sand accretion by an increase in the length of leaf petioles. Maun et al. (1996) showed that the $C$. pitcheri seedlings grew through the sand deposit by elongating the stem and leaf petioles, forming the new tillers, increasing the number of nodes and the length of internodes. Compared to one-off burial experiment (Sun et al., 2010), we found that continual burial (with the same magnitude of one-off burial) was more favorable for S. salsa seedlings growth, and seedlings could withstand more strong burials. The experimental results, to some extent, validated the correction of the Intermediate Disturbance Hypothesis. Similar result was reported by Maun et al. (1996) who found that continual burial to 4 (burial of $1 \mathrm{~cm}$ every 8 days) or $8 \mathrm{~cm}$ (burial of $2 \mathrm{~cm}$ every 8 days) depths exhibited greater vigorous growth of plants than one-off burial. One possible explanation for the greater stimulation is that continual burial maintains a low stressful environment around seedlings and the seedlings may adjust quickly. Simultaneously, seedling vigor may be triggered by moderate burial disturbances. The continual alteration of plant growth conditions, such as improved soil conditions (Disraeli, 1984), mycorrhizal fungi associations (Little and Maun, 1996), lowered water stress (Olson, 1958) and temporary escape from harmful soil pathogens (van der Putten et al., 1993), may be more favorable for the growth of plants than the sudden alteration. If a plant is completely inundated by one-off burial, it must divert all of its stored energy to the growing organs to emerge above the sediment surface (Harris and Davy, 1987). In contrast, the plants in the continual burial treatments recovered quickly and exhibited enhanced growth mainly because a dynamically buried plant has all or most of its leaf area intact and continues to grow unabated.

Under burial conditions, big size seedlings generally cannot be buried easily compared to small size seedlings and the chance for establishment is higher (Harris and Davy, 1987). Thus, successful establishment of seedlings, once emerged, will primarily depend on their ability to rapidly attain sufficient size. In the post-establishment phase, seedling growth rate, rather

Table 2

ANOVA results of seedling hypocotyl length, taproot diameter and length, and dry mass of Suaeda salsa at different continual burial depths after 51 days.

\begin{tabular}{|c|c|c|c|c|c|c|c|}
\hline \multirow[t]{2}{*}{ Parameters } & \multirow[t]{2}{*}{ Hypocotyl length } & \multirow[t]{2}{*}{ Taproot diameter } & \multirow[t]{2}{*}{ Taproot length } & \multicolumn{4}{|l|}{ Dry mass } \\
\hline & & & & Seedling & Root & Stem & Leaf \\
\hline MS & 32.475 & 0.229 & 1.495 & 0.401 & 0.005 & 0.018 & 0.224 \\
\hline$d f$ & 4 & 4 & 4 & 4 & 4 & 4 & 4 \\
\hline$F$ & 89.503 & 3.742 & 9.382 & 2.708 & 7.485 & 1.843 & 2.790 \\
\hline$p$ & $<0.001^{* * *}$ & $0.013^{*}$ & $<0.001^{* * *}$ & $0.049^{*}$ & $<0.001^{* * *}$ & 0.148 & $0.045^{*}$ \\
\hline
\end{tabular}

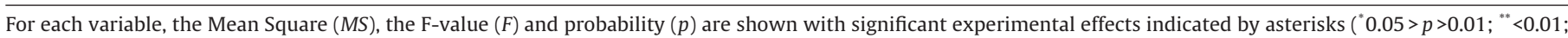
$\left.{ }^{* * *}<0.001\right)$. 

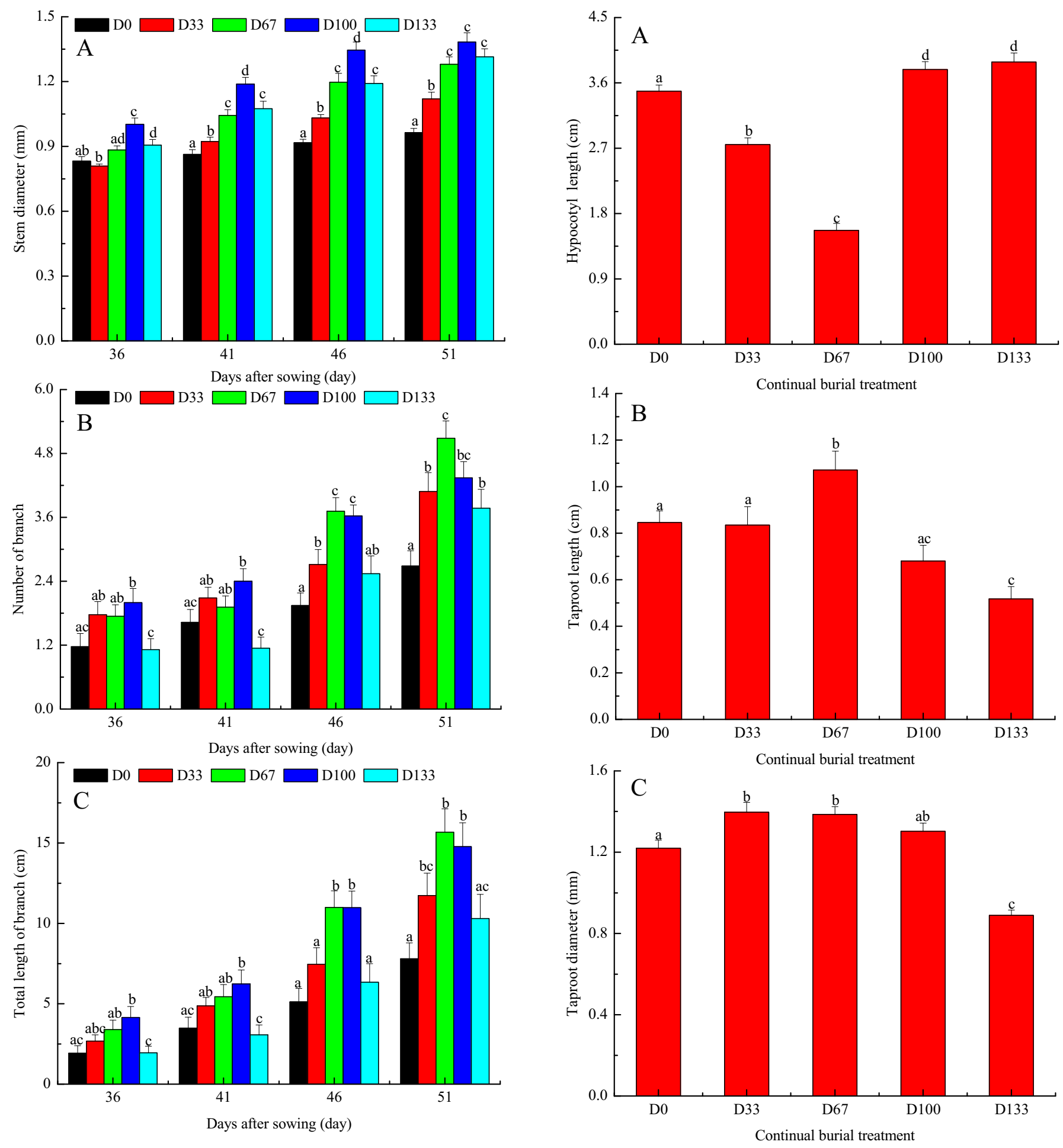

Fig. 3. Mean $( \pm \mathrm{SE})$ stem diameter $(\mathrm{A})$, number $(\mathrm{B})$ and length $(\mathrm{C})$ of branch of seedlings continually buried in sediment to depths of 0 (D0), 33\% (D33), 67\% (D67), $100 \%$ (D100) and 133\% (D133) of their mean height in different periods. For each period, values with the same superscript letters are not significantly different at $p<0.05$ according to Tukey's test

than seedling mass, was the most important determinant of continuing recruitment success (Dalling and Hubbell, 2002). In this study, both AHGR and RHGR of the D33 and D67 treatments were higher than those of the other treatments (Fig. 2), indicating that seedlings in the two treatments (especially at

Fig. 4. Mean ( \pm SE) hypocotyl $(A)$ and taproot $(B)$ length, and taproot diameter $(C)$ of seedlings continually buried in sediment to depths of 0 (D0), 33\% (D33), 67\% (D67), 100\% (D100) and 133\% (D133) of their mean height after 51 days. Values with the same superscript letters are not significantly different at $p<0.05$ according to Tukey's test.

the D33 treatment) probably had higher growth rate. Moreover, this study showed that a significant increase in dry mass of $S$. salsa seedlings was observed at shallow and moderate burial treatments (D33 and D67) compared to control (Fig. 5A). Simultaneously, an increase in the growth of 

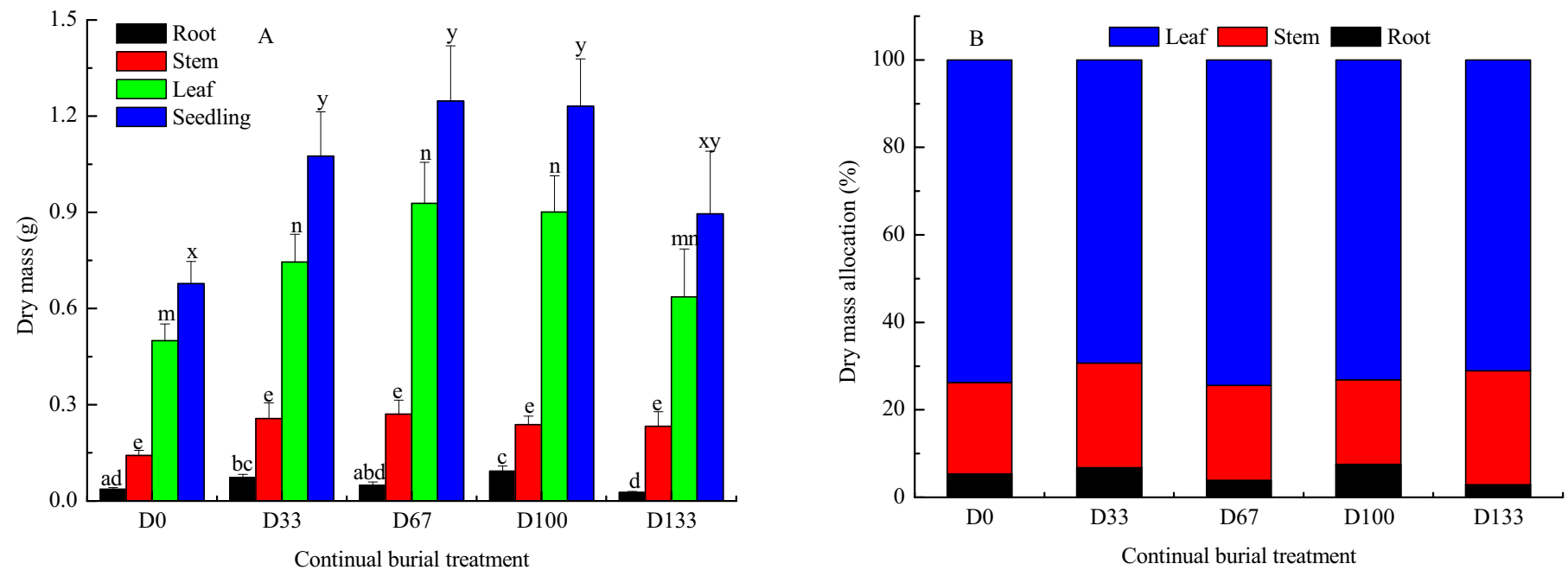

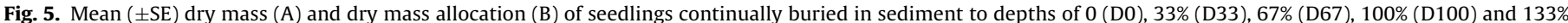
(D133) of their mean height after 51 days. Values with the same superscript letters are not significantly different at $p<0.05$ according to Tukey's test.

taproots was observed at the D33 and D67 treatments (Fig. 4B and $\mathrm{C}$ ). Therefore, we concluded that the dry mass increase and taproot growth probably had close correlation since the increase in the growth of taproots would provide more nutrients and proper growth conditions thus increasing the growth of shoots (Perumal and Maun, 2006). Similar results were reported by Cheplick and Grandstaff (1997) who showed that growth stimulation of partially buried seedlings of Triplasis purpurea was primarily caused by an increase in growth of roots. Perhaps, the most important factors would be an increase in S. salsa root mass (the values in the D33 and D67 treatments were 2.01 and 1.34 folds of D0 treatment, respectively) (Fig. 5A) and the expansion of considerable mycorrhizal fungi into the burial deposit, which would exploit the resources from the burial deposit, especially nitrogen or phosphorus for the benefit of plants (Koske and Polson, 1984). Although the dry mass of seedlings of the D100 treatment was less than those of the D67 treatment, the value was still higher than those of the other treatments (Fig. 5A). We considered that, based on above analyses, it was probably correlated with the greatest increase in root mass in the D100 treatment (Fig. 5A), which was favorable for the growth of shoots.

This experiment showed that, after being continually buried to different depths, $S$. salsa seedling stem did not form adventitious roots but its color changed from green to pink. This was very different with one-off burial experiment that the entire $S$. salsa seedling stem formed adventitious roots after being one-off buried to different depths for less than 4 weeks (Sun et al., 2010). Perhaps, the continual burials were not favorable for the formation of anaerobic condition which greatly influenced the formation of adventitious roots (Jackson, 1985). This study also indicated that the variations of taproot diameter and length of $S$. salsa seedlings were opposite to those of hypocotyl length (Fig. 4). With increasing burial depth (D67, D100 and D133), taproot diameter and length decreased while hypocotyl length increased, indicating that hypocotyl elongation might occur at the expense of development of the root system. Similar results were drawn by Maun et al. (1996) who showed that the elongation of $C$. pitcheri seedling stem and leaf petioles occurred at the expense of development of the root system and available energy was re-allocated to aboveground parts. Moreover, it was also anticipated that the dry mass allocation of $S$. salsa seedlings would be greatly changed with increasing continual burial depth, and this was tested in this experiment. Dry mass allocations to root and stem were significantly affected by burial depth, and the highest root-mass, stem-mass and leaf-mass ratios were observed in the D100, D133 and D67 treatments, respectively (Fig. 5B).

Compared to the one-off burial experiment, the dry mass allocation of different parts (root, stem and leaf) did not show strictly monotone increasing or decreasing with increasing continual burial depth, indicating that $S$. salsa might have a special resource allocation strategy to tolerate different burial stresses in the coastal marshes of the Yellow River estuary. The highest allocation to root in the D100 treatment was dependent on the greatest increase in root mass (Fig. 5A). The highest allocation to stem and the lowest allocation to root in the D133 treatment was mainly related to the hypocotyl elongation at the expense of development of the root system as mentioned above, while the highest allocation to leaf and the lower allocation to root in the D67 was correlated with the resource allocation of seedlings after being buried to moderate depth. In order to tolerate the moderate sediment episodes, $S$. salsa seedlings may allocate most resources and energy to the leaf, which was favorable for the photosynthetic activity and this, can also explain why the dry mass of seedlings and their aboveground parts reached the highest values in the D67 treatment.

\subsection{Adaptation to continual burial disturbances}

Tolerance of continual burial allows a species to extend its range through colonization area with sediment deposition, such as river shore and mudflat in the intertidal zone. As discussed before, $S$. salsa might have a special strategy to tolerate the continual burial stresses in the coastal marshes of the Yellow River estuary. As the burial depth reached $100 \%$ and $133 \%$ of seedling height although it would result in a great inhibitory on S. salsa seedling height, the greater stimulatory effect on stem diameter, number and length of branch and dry mass accumulation of seedlings were still existed. As the burial depth reached $67 \%$ of seedling height, the seedlings generally exhibited the greatest vigor. Some species may actually require continual burial of sediment to maintain high vigor (van der Putten et al., 1993; Halun et al., 2002; Wen et al., 2012). Taken in this sense, it was concluded that the continual burial of $2 \mathrm{~mm} \mathrm{~d}^{-1}$ would be favorable for the growth of $S$. salsa seedlings. Actually, the use of thin-layer deposition of dredged materials to restore Spartina alterniflora-dominated salt marsh in coastal Louisiana has been practiced effectively (Ford et al., 1999), and our study provided valuable information to improve 
restoration efforts of degraded $S$. salsa marsh during seedling growth. As mentioned previously, the $S$. salsa marshes near the Yellow River estuary exhibited different degraded statuses (Mou, 2010). During the restoration in the next step, S. salsa will be one of the most important species, and suitable environmental conditions can be selectively ameliorated to promote seedling growth. Based on the above discussions, we considered that the use of thin-layer continual burial $\left(2 \mathrm{~mm} \mathrm{~d}^{-1}\right)$ in practice to promote $S$. salsa seedling growth in degraded marshes would be very feasible.

Because this experiment was conducted in a greenhouse under controlled conditions, there were some difficulties in directly transplanting part of results to the field. For instance, complicated environment in field might decrease the positive effects of continual accretion of sediment, and the responses to continual burial might vary with seedlings. As mentioned previously, freshwater subsidy was also an important factor in maintaining $S$. salsa marshes. In this experiment, we mainly focused on the effects of sediment continual burial on seedling growth, while those of freshwater subsidy were not fully considered which, to some extent, affected the experimental results. Even so, the present findings of this experiment still had important significances, which could provide valuable information for us to understand the ecological adaptations of $S$. salsa to dynamic and strong sediment habitats, and theoretically explore effective restoration measures for the degraded $S$. salsa marshes from sediment disturbance perspective. In the future, field studies that consider both sediment continual burial and freshwater subsidy should be done in order to verify the practical importance of the present findings on ecological restoration.

\section{Acknowledgements}

The authors would like to acknowledge the two anonymous reviewers for their constructive comments on this paper. This study was financially supported by the National Natural Science Foundation of China (No. 41371104, 41171424), the Key Research Program of the Chinese Academy of Sciences (No. KZZD-EW-14), the "1-35" Strategy Plan Program of the Yantai Institute of Coastal Zone Research of the Chinese Academy of Sciences (No. Y254021031), the Open Research Fund Program of Shandong Key Laboratory for Yellow River Delta Eco-Environmental Science, Binzhou, China (No. 2012KFJJ03), and the Nature Science Foundation of Shandong Province (No. ZR2013CQ007).

\section{References}

Baldwin, K.A., Maun, M.A., 1983. Microenvironment of Lake Huron sand dunes. Can. J. Bot. 61, 241-255.

Brown, J.F., 1997. Effects of experimental burial on survival, growth, and resource allocation of three species of dune plants. J. Ecol. 85, 151-158.

Chandrasekara, W.U., Frid, C.L.J., 1998. A laboratory assessment of the survival and vertical movement of two epibenthic gastropod species, Hydrobia ulvae (Pennant) and Littorina littorea (Linnaeus), after burial in sediment. J. Exp. Mar. Biol. Ecol. 221, 191-207.

Chen, H., Maun, M.A., 1999. Effects of sand burial depth on seed germination and seedling emergence of Cirsium pitcheri. Plant Ecol. 140, 53-60.

Cheplick, G.P., Grandstaff, K., 1997. Effects of sand burial on purple sandgrass (Triplasis purpurea): the significance of seed heteromorphism. Plant Ecol. 133, 79-89.

Cui, B.S., He, Q., Zhao, X.S., 2008. Response on the ecological thresholds of Suaed salsa to the environmental gradients of water table depth and soil salinity. Acta Ecol. Sin. 28 (4), 1408-1418.

Cui, B.S., Yang, Q.C., Yang, Z.F., Jiang, K.J., 2009. Evaluating the ecological performance of wetland restoration in the Yellow River Delta. China. Ecol. Eng. 35, 1090-1103.

Dalling, J.W., Hubbell, S.P., 2002. Seed size, growth rate and gap microsite conditions as determinants of recruitment success for pioneer species. J. Ecol. 90, 557-568.

Deng, Z.F., An, S.Q., Zhao, C.J., Chen, L., Zhou, C.F., Zhi, Y.B., Li, H.L., 2008. Sediment burial stimulates the growth and propagule production of Spartina alterniflora Loisel. Estuar. Coast. Shelf Sci. 76, 818-826.

Disraeli, D.J., 1984. The effect of sand deposits on the growth and morphology of Ammophila breviligulata. J. Ecol. 72, 145-154.

Ford, M.A., Cahoon, D.D., Lynch, J.C., 1999. Restoring marsh elevation in a rapidly subsiding salt marsh by thin layer deposition of dredged material. Ecol. Eng. 12, 189-205.
Franks, S.J., Peterson, C.J., 2003. Burial disturbance leads to facilitation among coastal dune plants. Plant Ecol. 168, 13-21.

Halun, Z., Terrados, J., Borum, J., 2002. Experimental evaluation of the effects of siltation-derived changes in sediment conditions on the Philippine seagrass Cymodocea rotundata. J. Exp. Mar. Biol. Ecol. 279, 73-87.

Harris, D., Davy, A.J., 1987. Seedling growth in Elymus farctus after episodes of burial with sand. Ann. Bot.-London 61, 147-157.

He, Y.H., Zhao, H.L., Zhao, X.Y., Liu, X.P., 2008. Effects of different sand burial depths on growth and biomass allocation in Caragana microphylla seedlings. Arid Land Geogr. 31 (5), 701-706.

Jackson, M.B., 1985. Ethylene and response of plants to soil waterlogging and submergence. Ann. Rev. Plant Physiol. 36, 145-175.

Koske, R.E., Polson, W.R., 1984. Are VA mycorrhizae required for sand dune stabilization? Bioscience 34, 420-424.

Lee, S.K., Tan, W.H., Havanond, S., 1996. Regeneration and colonization of mangrove on clay-filled reclaimed land in Singapore. Hydrobiologia 319, 23-35.

Li, Q.Y., Zhao, W.Z., Fang, H.Y., 2006. Effects of sand burial depth and seed mass on seedling emergence and growth of Nitraria sphaerocarpa. Plant Ecol. 185, $191-198$.

Li, S.H., Zhou, D.M., Luan, Z.Q., Pan, Y., Jiao, C.C., 2011. Quantitative simulation on soil moisture contents of two typical vegetation communities in Sanjiang Plain, China. Chin. Geogr. Sci. 22 (6), 723-733.

Little, L.R., Maun, M.A., 1996. The Ammophila problem revisited: a role for mycorrhizal fungi. J. Ecol. 84, 1-7.

Liu, Z.M., Yan, Q.L., Baskin, C.C., Ma, J.L., 2006. Burial of canopy-stored seeds in the annual psammophyte Agriophyllum squarrosum Moq. (Chenopodiaceae) and its ecological significance. Plant Soil 288, 71-80.

Maun, M.A., 1994. Adaptation enhancing survival and establishment of seedlings on coastal dune systems. Vegetatio 111, 59-70.

Maun, M.A., 1996. The effects of burial by sand on survival and growth of Calamovilfa longifolia. Ecoscience 3, 93-100.

Maun, M.A., 1998. Adaptations of plants to burial in coastal sand dunes (1997 George Lawson Medal Review). Can. J. Bot. 76, 713-738.

Maun, M.A., Elberling, H., D'Ulisse, A., 1996. The effects of burial by sand on survival and growth of Pitcher's thistle (Cirsium pitcheri) along Lake Huron. J. Coast. Conserv. 2, 3-12.

Maun, M.A., Lapierre, J., 1984. The effects of burial by sand on Ammophila breviligulata. J. Ecol. 72, 827-839.

Maun, M.A., Riach, S., 1981. Morphology of caryopses, seedlings and seedling emergence of the grass Calamovilfa longifolia from various depths in sand. Oecologia 49, 137-142.

Mou, X.J., (Master degree dissertation) 2010. Study on the Nitrogen Biological Cycling Characteristics and Cycling Model of Tidal Wetland Ecosystem in Yellow River estuary. Yantai Institute of Coastal Zone Research, Chinese Academy of Sciences, Yantai.

Olson, J.S., 1958. Rates of succession and soil changes on southern Lake Michigan dunes. Bot. Gazette 119, 125-170.

Perumal, V.J., Maun, M.A., 2006. Ecophysiological responses of dune species to experimental burial under field and controlled conditions. Plant Ecol. 184 89-104.

Redmann, R.E., Qi, M.Q., 1992. Impacts of seeding depth on emergence and seedling structure in eight perennial grasses. Can. J. Bot. 70, 133-139.

Sun, Z.G., Mou, X.J., Lin, G.H., Wang, L.L., Song, H.L., Jiang, H.H., 2010. Effects of sediment burial disturbance on seedling survival and growth of Suaeda salsa in the tidal wetland of the Yellow River estuary. Plant Soil 337, 457-468.

Sun, Z.G., Mou, X.J., Sun, J.K., Song, H.L., Yu, X., Wang, L.L., Jiang, H.H., Sun, W.L., Sun, W.G., 2012. Nitrogen biological cycle characteristics of seepweed (Suaeda salsa) wetland in intertidal zone of Huanghe (Yellow) River estuary. Chin. Geogr. Sci. 22 (1), 15-28.

Sykes, M.T., Wilson, J.B., 1990. An experimental investigation into the response of New Zealand sand dune species to different depths of burial by sand. Acta Bot. Neerl. 39, 171-181.

Terrados, J., Tampahnya, U., Srichai, N., Boromthanarath, S., Panapitukkul, N., Duarte, C.M., 1997. The effect of increased sediment accretion on the survival and growth of Rhizophora apiculata seedlings. Estuar. Coast. Shelf Sci. 45, 697-701.

Thampanya, U., Vermaat, J.E., Terrados, J., 2002. The effects of increasing sediment accretion on the seedlings of three common Thai mangrove species. Aquat. Bot. 74, 315-325.

van der Putten, W.H., van Dijk, C., Peters, B.A.M., 1993. Plant-specific soil-borne diseases contribute to succession in foredune vegetation. Nature 362, 53-55.

Wen, B.L., Liu, X.T., Li, X.J., Yang, F.Y., Li, X.Y., 2012. Restoration and rational use of degraded saline reed wetlands: a case study in western Songnen Plain, China. Chin. Geogr. Sci. 22 (2), 167-177

Xu, X.G., Guo, H.H., Chen, X.L., Lin, H.P., Du, Q.L., 2002. A multi-scale study on land use and land cover quality change: the case of the Yellow River Delta in China. GeoJournal 56 (3), 177-183.

Yang, H.L., Cao, Z.P., Dong, M., Ye, Y.Z., Huang, Z.Y., 2007. Effects of sand burying on caryopsis germination and seedling growth of Bromus inermis Leyss. Chin. J. Appl. Ecol. 18 (11), 2438-2443.

Zhang, J., Maun, M.A., 1990. Effects of sand burial on seed germination, seedling emergence, survival, and growth of Agropyron psammophilum. Can. J. Bot. 68, 304-310.

Zhao, W.Z., Li, Q.Y., Fang, H.Y., 2007. Effects of sand burial disturbance on seedling growth of Nitraria sphaerocarpa. Plant Soil 295, 95-102. 